\title{
Atividade amidolítica e de invertase ácida solúvel em tubérculos de bata- ta armazenados sob duas condições de temperatura
}

\author{
Marilice Chapper ${ }^{1}$; Marcos Antonio Bacarin ${ }^{2}$; Arione da S. Pereira ${ }^{3}$; Nei F. Lopes ${ }^{3}$ \\ ${ }^{1}$ Colégio Agrícola Visconde da Graça, UFPel, 96010-900 Pelotas-RS; ${ }^{2}$ UFPel, 96010-900 Pelotas-RS; E-mail: bacarin@ ufpel.tche.br \\ (autor para correspondência) (Bolsista CNPq); ${ }^{3}$ Embrapa Clima Temperado, 96001-970 Pelotas-RS (Bolsista CNPq)
}

\section{RESUMO}

Determinou-se as atividades amidolítica e da invertase ácida solúvel nos tubérculos de batata das cultivares Pérola e Atlantic. Os tubérculos foram produzidos no cultivo de outono e de primavera de 1999, em Pelotas (RS). Imediatamente após a colheita, os tubérculos foram divididos em dois lotes e armazenados por 40 dias, em duas condições de temperatura: ambiente $\left(21 \pm 3^{\circ} \mathrm{C}\right.$, para a produção de outono; $24 \pm 2^{\circ} \mathrm{C}$, para a produção de primavera) e refrigeração $\left(2 \pm 1^{\circ} \mathrm{C}\right)$. Em intervalos regulares de dez dias, a partir da colheita (tempo zero), foram coletadas amostras dos tubérculos para determinação dos teores de proteínas solúveis totais e atividades da invertase ácida e amidolítica. Os teores de proteínas solúveis totais não diferiram nas duas condições de armazenamento. As atividades enzimáticas aumentaram quando os tubérculos dos dois genótipos foram expostos a baixas temperaturas. Os tubérculos mantidos em temperatura ambiente tiveram atividade específica da invertase praticamente constante, porém muito baixa quando comparada aos tubérculos refrigerados. A atividade específica da invertase foi superior nos tubérculos do cultivo de outono, em função de períodos de baixas temperaturas a que foram expostos antes da colheita.

Palavras-chave: Solanum tuberosum, refrigeração, metabolismo de carboidratos.

\section{ABSTRACT}

Amidolytic and an acid soluble invertase activities in potato tubers stored under two temperature conditions

The amidolytic and invertasic activities in tubers of two potato genotypes (Perola and Atlantic) were determined. The tubers were produced in autumn and spring crops from 1999, in Pelotas, Rio Grande do Sul State, Brazil. Immediately after harvesting, the tubers were divided in two lots and stored for 40 days under two conditions: room temperature $\left(21 \pm 3^{\circ} \mathrm{C}\right.$, for the autumn crop; $24 \pm 2^{\circ} \mathrm{C}$, for the spring crop) and refrigeration $\left(2 \pm 1^{\circ} \mathrm{C}\right)$. In a regular ten-day interval, starting at harvest (time zero), tubers samples of the two cultivars were collected from the two storage conditions and evaluated for soluble protein content, amidolytic and invertasic activities. The soluble protein content was not affected by the storage temperature. Enzymatic activities of both cultivars increased when tubers were exposed to low temperature. Enzymatic activity remained practically constant in potatoes kept at room temperature, but much lower than in refrigerated tubers. The activity of specific invertase was higher in tubers of the autumn crop due to the exposure to low temperatures before harvesting.

Keywords: Solanum tuberosum, refrigeration, carbohydrates metabolism.

\section{(Recebido para publicação em 29 de junho de 2003 e aceito em 5 de maio de 2004)}

$\mathrm{N}$ o Brasil a produção de batata (Solanum tuberosum L.) estendese por quase todo o ano, a fim de atender às necessidades de suprimento da demanda de consumo in natura e da indústria. Parte da produção é armazenada em curto prazo em diferentes condições. As baixas temperaturas mantêm o produto, mas causam diminuição da qualidade, em virtude da elevação dos teores de açúcares nos tecidos (Burton, 1989), que provocam o escurecimento durante o processamento em altas temperaturas, tornando-o comercialmente inaceitável (Davies e Viola, 1992). O acúmulo de açúcares redutores nos tubérculos mantidos sob baixas temperaturas é o resultado da conversão do amido (Rees et al., 1981). Embora este fenômeno esteja bem descrito, as causas e os mecanismos não estão ainda bem estabelecidos, existindo evidências de que um fino controle metabólico esteja envolvido neste processo. A senescência das membranas do amiloplasto da batata, decorrente de baixas temperaturas (O'donoghue et al., 1995), ou mesmo a fragilidade destas membranas, podem estar associadas ao adoçamento (Isherwood, 1976).

Muitos argumentos têm sido utilizados para explicar o acúmulo de açúcares induzidos pelo frio, incluindo o aumento na atividade de uma ou mais enzimas que degradam o amido (Cochrane et al., 1991; Claassen et al., 1993; Cottrell et al., 1993), a maior concentração de hexose fosfato como resultado da fosfofrutocinase e de outras enzimas na glicólise (Pollock e Rees, 1975; Dixon e Rees, 1980; Trevanion e Kruger, 1991), o aumento na atividade das enzimas envolvidas na síntese da sacarose como a sacarose fosfato sintase (Sowokinos, 1990) e o aumento na atividade da invertase (Richardson et al., 1990; Pressey e Shaw, 1966).
Embora haja forte indicação, pela comparação entre cultivares e transformantes, que a invertase é importante no controle da velocidade de degradação da sacarose para açúcares redutores, sua atividade não está correlacionada com o acúmulo total de açúcar, que ocorre somente em temperaturas de $5^{\circ} \mathrm{C}$ (Deiting et al., 1998), é identificada aumento na atividade de amidolítica sob refrigeração (Richardson et al., 1990; Zrenner et al., 1996).

As invertases citoplasmáticas neutras e alcalinas são bem menos caracterizadas, mas em contraste com as invertases ácidas, essas enzimas parecem ser específicas para sacarose, ao passo que as invertases ácidas além da sacarose, hidrolisam outros oligossacarídeos contendo resíduos de ß-frutose, tais como rafinose e estaquiose (Sturm, 1999). A expressão da invertase do vacúolo e da parede ce- 


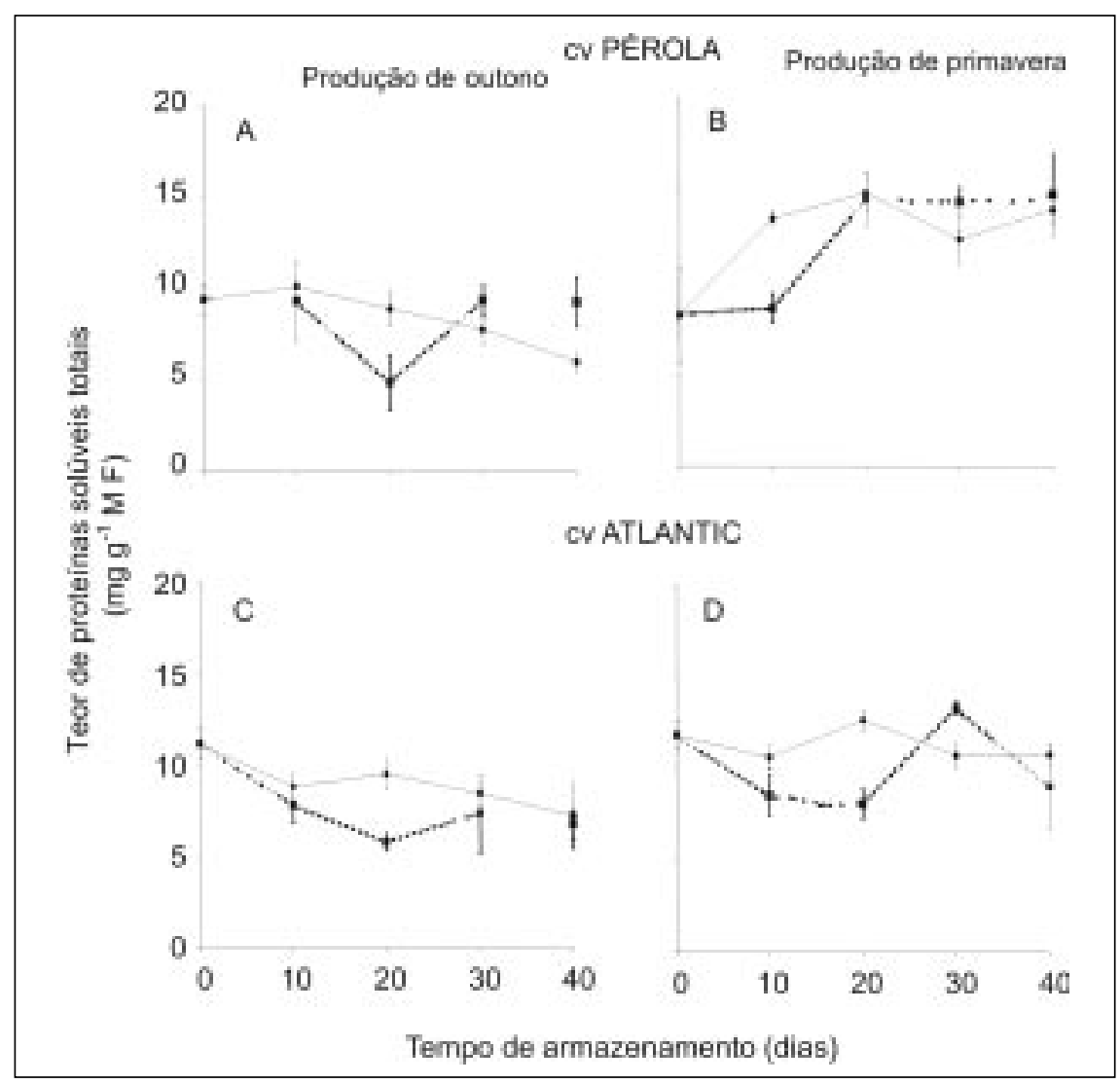

Figura 1. Teor de proteínas solúveis totais em tubérculos de batata das cultivares Pérola e Atlantic, produzidos no outono e na primavera/99, em função do tempo e da temperatura de armazenamento [ambiente: $24 \pm 2^{\circ} \mathrm{C}(-)$, para produção de primavera, e $21 \pm 3^{\circ} \mathrm{C}(-)$, para produção de outono e refrigerado: $2 \pm 1^{\circ} \mathrm{C}(\ldots \ldots \ldots \ldots \ldots)$. A barra indica o desvio padrão da média. Pelotas, Embrapa Clima Temperado, 2002.

lular conduz a uma drástica redução no conteúdo de sacarose do tubérculo e a um correspondente aumento no conteúdo de glicose (Sonnewald et al., 1997). Em muitas espécies de plantas, a atividade da invertase ácida aumentou em resposta a fitohormônios (Morris e Arthur, 1984; Ehness e Roitsch, 1997). Entretanto, ainda não está claro se esses efeitos são devidos à regulação direta dos genes da invertase pelos hormônios vegetais ou estimulados pela proliferação celular, criando-se novos drenos para sacarose, sendo que a função das invertases ácidas nesses tecidos, é hidrolisar a sacarose sob condições onde há alta demanda de hexoses (Sturm, 1999).

Em órgãos dreno armazenadores de açúcar, como os frutos, a alta atividade da invertase ácida parece estar relacionada com o acúmulo de hexoses, que também ocorre durante o armazenamento de tubérculos de batata no frio. Assim, a função da invertase ácida solúvel, neste processo de póscolheita, é de regular a composição de açúcar. O objetivo do presente trabalho foi determinar a atividade específica de enzimas amidolíticas e de uma invertase ácida solúvel em tubérculos de dois genótipos de batata, mantidos sob condições de temperatura ambiente e sob refrigeração, durante o armazenamento pós-colheita.

\section{MATERIAL E MÉTODOS}

Foram utilizadas duas cultivares de batata: a 'Pérola' foi recentemente lançada pela Embrapa Clima Temperado, para o processamento na forma de "batata palha" (Pereira et al., 2000); a cultivar Atlantic é originária dos Estados Unidos, sendo especialmente indicada para fritura na forma de fatias (chips), podendo ser utilizada também para a produção de "batata palha" (Melo, 1999).
Os tubérculos foram produzidos no cultivo de outono e de primavera de 1999, no campo experimental da Embrapa Clima Temperado. Nos dois cultivos foram realizados os tratos culturais recomendados para a cultura na região, sendo as temperaturas médias diárias inferiores à normal da região. Durante o cultivo de outono, os tubérculos foram expostos a 107 horas de frio, enquanto que os de primavera a 44 horas de temperaturas inferiores ou iguais a $6,2^{\circ} \mathrm{C}$. Imediatamente após cada colheita, os tubérculos foram transferidos para o laboratório da UFPel e divididos em dois lotes, padronizados quanto ao tamanho e armazenados em condições de ambiente, cuja temperatura média diária foi de $21 \pm 3^{\circ} \mathrm{C}$ para o plantio de outono e de $24 \pm 2^{\circ} \mathrm{C}$ para o de primavera e sob refrigeração, de $2 \pm 1^{\circ} \mathrm{C}$, ambos na ausência de luz.

Amostras dos tubérculos sadios foram coletadas para análise em intervalos regulares de dez dias, iniciando-se imediatamente após a colheita (tempo zero), durante 40 dias de armazenamento, perfazendo um total de cinco coletas. As amostras dos tubérculos foram coletadas em cada tratamento e acondicionadas individualmente em recipientes, contendo soluções adequadas até o momento das análises. Em cada amostragem, foram determinados os teores de proteínas solúveis totais e as atividades da invertase ácida e amidolítica total.

Para a estimativa da atividade da invertase ácida (E.C. 3.2.1.26), foi utilizada a metodologia descrita por Robinson et al. (1988), a qual consiste na extração da enzima com tampão fosfato $0,2 \mathrm{M}, \mathrm{pH} 5,0$, com posterior centrifugação a $10.000 \mathrm{~g}$, obtendo-se o sobrenadante extrato protéico bruto. A partir do extrato protéico bruto foi realizada a determinação da atividade da invertase ácida, baseada na formação de açúcares redutores. Para tanto, utilizouse um meio de reação contendo sacarose $250 \mathrm{mM}$, tampão acetato $0,1 \mathrm{M}, \mathrm{pH}$ 5,0 com volume final de $2,5 \mathrm{ml}$. Ao meio de reação foi adicionado $1,5 \mathrm{ml}$ de extrato protéico, sendo este mantido sob temperatura constante de $37^{\circ} \mathrm{C}$, por 30 minutos. A seguir, a reação foi paralisada pela adição de $1 \mathrm{ml}$ de reativo de 
Nelson (Nelson, 1944) e estimados os teores de açúcares redutores formados, utilizando-se glicose como padrão.

Os teores de açúcares redutores inicialmente presentes nas amostras, antes da incubação com a enzima, e os formados após a ação da enzima foram determinados, estimando-se por diferença a atividade da invertase ácida. A atividade amidolítica total foi determinada, segundo descrito por Robinson et al. (1988), baseada no consumo de amido pelo extrato protéico. Os teores de proteínas solúveis totais foram quantificados a partir do extrato protéico bruto pelo método do Biureto (Gornall et al., 1949), sendo utilizados para estimar as atividades específicas das enzimas.

Considerando cada período de cultivo como ensaio independente, os mesmos foram conduzidos em um delineamento inteiramente casualizado no esquema fatorial $(2 \times 5)$, sendo dois genótipos e cinco épocas de coleta, com quatro repetições, considerando-se cada tubérculo como unidade experimental. Após a análise de variância, as médias foram comparadas pelo teste de Duncan a $5 \%$ de probabilidade.

\section{RESULTADOS E DISCUSSÃO}

Nos tubérculos produzidos no outono, os teores de proteínas solúveis totais em ambas condições de armazenamento foram similares para as duas cultivares (Figura 1). No entanto, aos 40 dias, esses teores foram levemente superiores nos tubérculos da Pérola, sob refrigeração, e da cultivar Atlantic, em condições de ambiente. Os tubérculos produzidos na primavera (Figura 1), também apresentaram similaridade nos teores de proteínas solúveis totais, entre as duas condições de armazenamento. Entretanto, os tubérculos da 'Pérola' apresentaram uma concentração levemente superior de proteínas em relação à cultivar Atlantic, tanto sob refrigeração quanto em condições de ambiente, durante todo o período de armazenamento.

Comparando as duas cultivares entre os períodos de cultivo, verificou-se que os teores de proteínas solúveis totais nos tubérculos de primavera foram

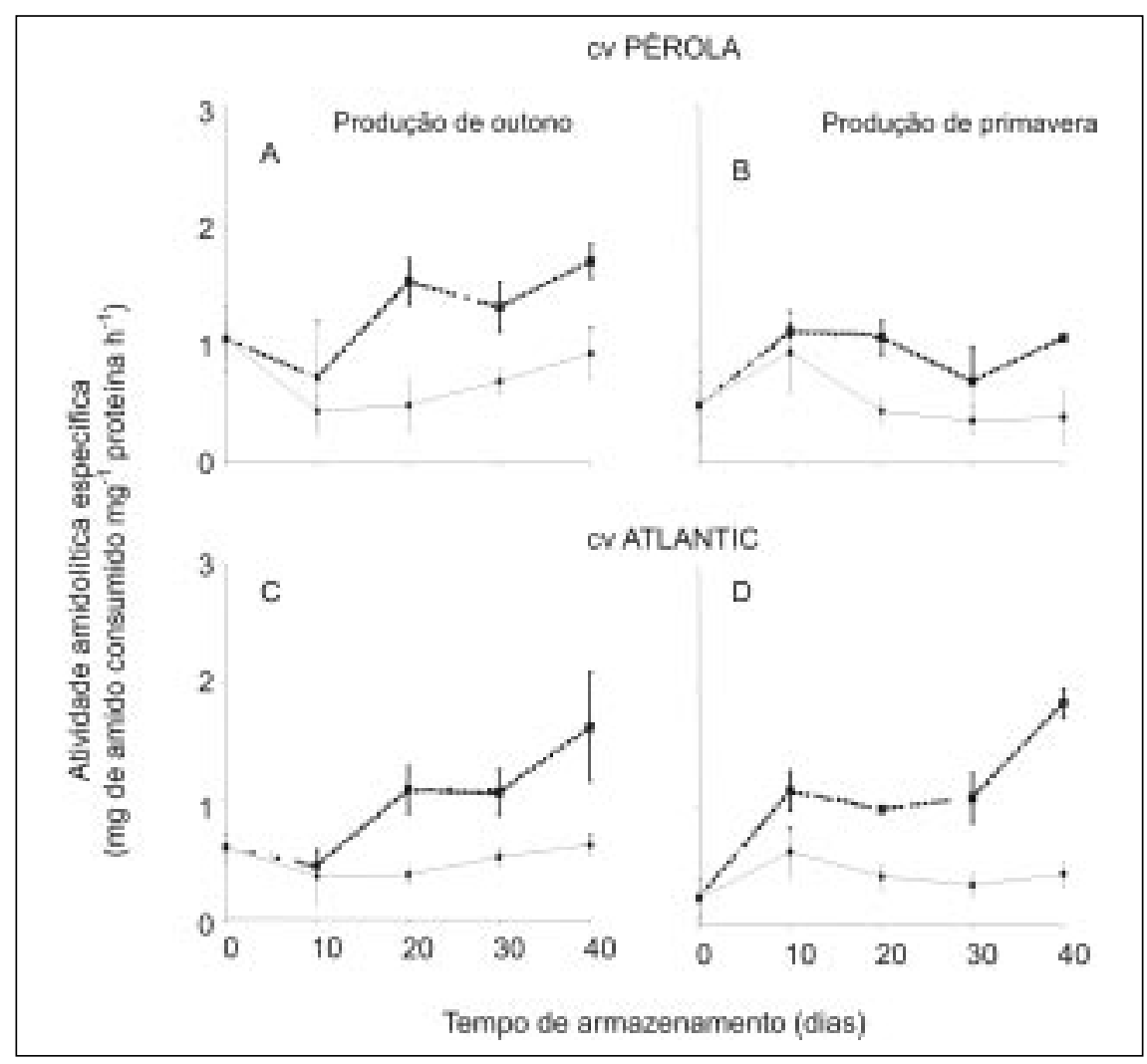

Figura 2. Atividade amidolítica específica em tubérculos de batata das cultivares Pérola e Atlantic, produzidos no outono e na primavera/99, em função do tempo e da temperatura de armazenamento [ambiente: $24 \pm 2^{\circ} \mathrm{C}(-)$, para produção de primavera, e $21 \pm 3{ }^{\circ} \mathrm{C}(-)$ ], para produção de outono; refrigerado: $\left.2 \pm 1^{\circ} \mathrm{C}(\ldots \ldots \ldots \ldots \ldots)\right]$. A barra indica o desvio padrão da média. Pelotas, Embrapa Clima Temperado, 2002.

superiores aos de outono, sendo que para os tubérculos da 'Pérola' este aumento foi mais expressivo. Aparentemente, porque os tubérculos oriundos da produção de outono desenvolveram-se em condições de temperaturas e fotoperíodos decrescentes, ao contrário, durante o cultivo de primavera, os tubérculos cresceram sob temperaturas $\mathrm{e}$ fotoperíodos ascendentes.

Os teores de proteínas solúveis totais estão de acordo com os dados citados por Pinto et al. (1993), que não encontraram alteração significativa na proteína total, durante prolongado armazenamento de tubérculos maduros a $7^{\circ} \mathrm{C}$. Resultado similar foi relatado por Hoff et al. (1978), que verificaram apenas pequenas diferenças nos teores de proteínas, após armazenamento dos tubérculos por 40 dias à temperatura ambiente.

As atividades amidolítica nos tubérculos sob refrigeração aumentaram, nos dois genótipos e períodos de cultivo, comparadas às condições de ambiente (Figura 2). Nos tubérculos de outono, houve uma elevação na atividade específica das amilases entre 10 e 20 dias de armazenamento. Os tubérculos da 'Pérola' apresentaram, na média, atividade específica amidolítica inicial maior (1,04 mg amido consumido $\mathrm{mg}^{-1}$ proteína $\left.\mathrm{h}^{-1}\right)$ do que a verificada para a 'Atlantic' (0,60 mg amido consumido $\mathrm{mg}^{-1}$ proteína $\left.\mathrm{h}^{-1}\right)$. Contudo, aos 40 dias de armazenamento sob refrigeração, a atividade foi semelhante nos tubérculos das duas cultivares $(1,69$ e $1,62 \mathrm{mg}$ amido consumido $\mathrm{mg}^{-1}$ proteína $\mathrm{h}^{-1}$, respectivamente, Pérola e Atlantic). Por outro lado, a atividade das amilases foi praticamente constante nos tubérculos de ambas cultivares armazenados sob temperatura ambiente (Figura 2A e C).

Nos tubérculos produzidos na primavera, em ambas as cultivares, a atividade amidolítica inicial, foi inferior à de outono, verificando-se também uma elevação na atividade anterior dos dez dias 


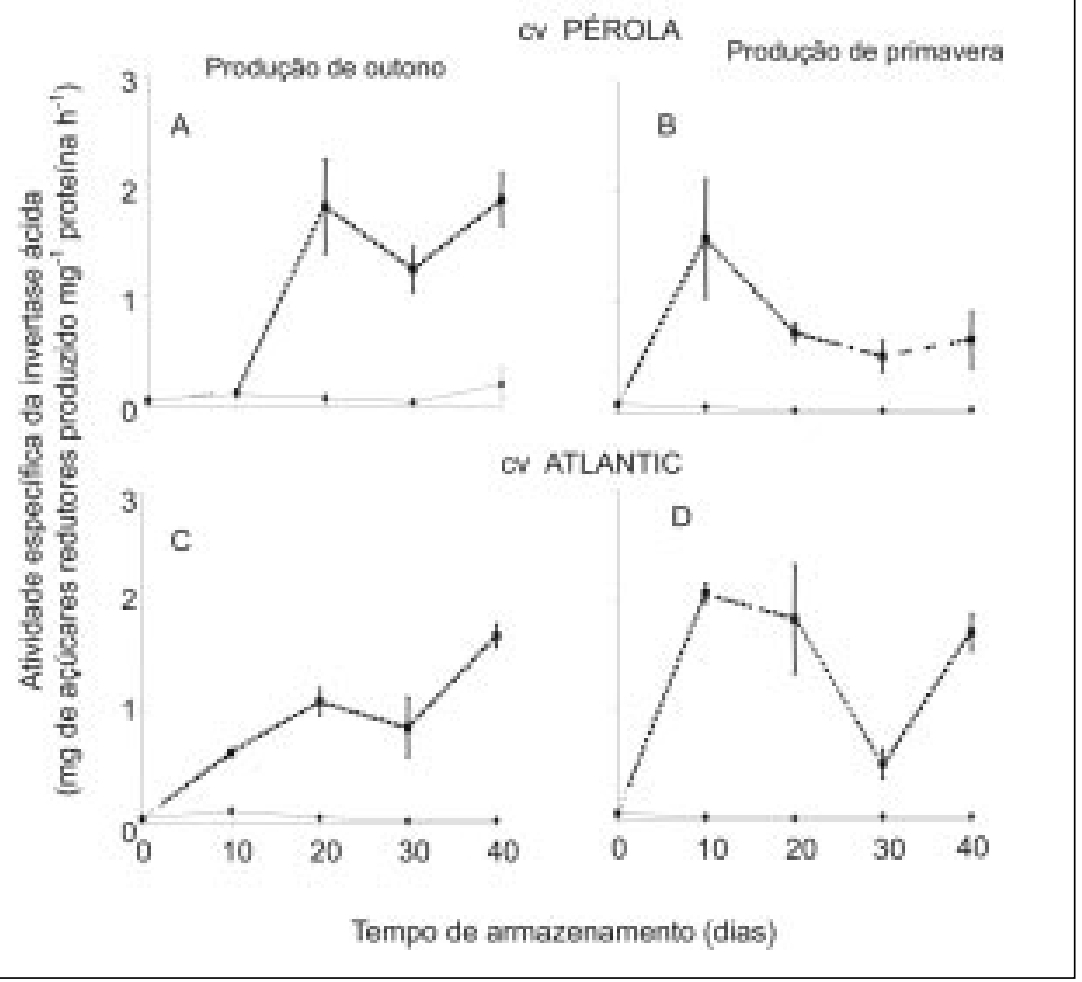

Figura 3. Atividade específica de invertase ácida em tubérculos de batata das cultivares Pérola e Atlantic, produzidos no outono e na primavera/99, em função do tempo e da temperatura armazenamento [ambiente: $24 \pm 2^{\circ} \mathrm{C}(-)$, para a produção de primavera, e $21 \pm 3^{\circ} \mathrm{C}$ (一), para a produção de outono; refrigerado: $\left.2 \pm 1^{\circ} \mathrm{C}(\ldots \ldots \ldots \ldots \ldots)\right]$. A barra indica $\mathrm{o}$ desvio padrão da média. Pelotas, Embrapa Clima Temperado, 2002.

após o inicio do armazenamento, para as duas condições (refrigeração e ambiente) (Figura 2B e D).

As baixas temperaturas ocorridas durante o ciclo de desenvolvimento das plantas de outono justificam essas diferenças nas atividades de amilases. Sabe-se também, que a baixa temperatura leva a um aumento na atividade de uma forma específica de amilase em tubérculos de batata, e fornece evidências de que esta forma de amilase induzida pelo frio poderá contribuir para a regulação do adoçamento sob esta condição (Deiting et al., 1998).

Nos tubérculos de primavera, houve uma elevação na atividade específica das amilases total antes de dez dias de armazenamento. A partir de 30 dias de armazenamento, os tubérculos de ambas as cultivares submetidos à refrigeração, apresentaram uma elevação na atividade da amidolítica, sendo mais acentuada nos tubérculos da 'Atlantic'. Tal elevação resultou que aos 40 dias os tubérculos da cv. Atlantic apresentaram atividade significativamente superior (1,87 mg amido consumido $\mathrm{mg}^{-1}$ proteí- na $\left.\mathrm{h}^{-1}\right)$ aos da 'Pérola' (1,05 mg amido consumido $\mathrm{mg}^{-1}$ proteína $\mathrm{h}^{-1}$ ).

A atividade da invertase estudada aumentou acentuadamente nos tubérculos submetidos à refrigeração, em ambas cultivares e cultivos, em relação aqueles sob condição de ambiente (Figura 3).

A atividade específica da invertase ácida solúvel nos tubérculos de outono aumentou após 10 dias de armazenamento sob refrigeração, sendo que aos 40 dias a atividade foi maior nos tubérculos da 'Pérola' (1,88 mg açúcares redutores produzidos $\mathrm{mg}^{-1}$ proteína $\left.\mathrm{h}^{-1}\right)$ do que a 'Atlantic' $(1,70 \mathrm{mg}$ açúcares redutores produzidos $\mathrm{mg}^{-1}$ proteína $\mathrm{h}^{-1}$ ).

Os tubérculos das duas cultivares mantidos sob temperatura ambiente, tiveram atividade praticamente constante, porém muito baixa quando comparada com os submetidos ao frio. A taxa de produção de açúcares redutores, aos 40 dias, foi ligeiramente superior nos tubérculos da 'Pérola' comparada com os da 'Atlantic'.

Os tubérculos de primavera, das duas cultivares, tiveram um pico na atividade da invertase aos dez dias, sob baixas temperaturas. Outro pico ocorreu aos 40 dias, tendo os tubérculos da cultivar Atlantic apresentado atividade da invertase cerca de três vezes maior do que os da 'Pérola'. Por outro lado, os tubérculos armazenados à temperatura ambiente mostraram baixíssima produção de açúcares redutores, em ambas cultivares.

Tubérculos da 'Pérola' colhidos em junho (outono), sob as duas condições de armazenamento, tiveram maiores atividades da invertase e da amilase específicas do que aqueles colhidos em dezembro (primavera).

É possível que as baixas temperaturas, ocorridas durante o outono, tenham inativado ou reduzido a atividade do inibidor da invertase. Em condições de temperaturas mais elevadas, como as ocorridas na primavera, a ação da invertase não foi tão proeminente e provavelmente a atividade do inibidor estivesse maior. Esses resultados estão de acordo com os encontrados por Pressey e Shaw (1966). Esses pesquisadores observaram que o nível do inibidor da invertase diminui quando exposto a baixas temperaturas aumentando novamente com a exposição a altas temperaturas. Sabe-se que a localização da invertase e o sítio de aumento na produção de hexose podem causar profundos efeitos na fisiologia do tubérculo (Sonnewald et al., 1997).

Considerando os resultados pode-se concluir que as atividades enzimáticas pós-colheita são influenciadas pelas condições ambientais durante o cultivo das plantas e pelo genótipo; Os teores de proteínas solúveis totais nos tubérculos não são marcadamente afetados pelas condições climáticas durante o cultivo, nem pelo genótipo ou condições de armazenamento; Baixas temperaturas no armazenamento dos tubérculos induzem aumentos nas atividades da invertase ácida e da amilase específicas; As atividades de amilases e invertases dos tubérculos da 'Pérola', de primavera, são menos sensíveis à refrigeração.

\section{AGRADECIMENTOS}

Pelo financiamento do presente trabalho: MCT/CNPq - Edital Universal, da FAPERGS - Edital PROADE. 


\section{LITERATURA CITADA}

BURTON, W.G. The Potato. Harlow: Longman Scientific and Technical. 1989.

CLAASSEN, P.A.M.; BUDDE, M.A.W.; CALKER, M.H. Increase in phosphorylase activity during cold-induced sugar accumulation in potato tubers. Potato Research, v.36, p.205-217. 1993.

COCHRANE, M.P.; DUFFUS, C.M.; ALLISON, M.J.; MACKAY, G.R. Amylolytic activity in stored potato tubers. 2. The effect of lowtemperature storage on the activities of á-âamylase \& á-glucosidase in potato tubers. Potato Research, v.34, p.333-341. 1991.

COTTRELL, J.E.; DUFFUS, C.M.; PATERSON, L.; MACKAY, G.R.; ALLISON, M.J.; BAIN, H. The effect of storage temperature on reducing sugar concentration and the activities of three amylolytic enzymes in tubers of the cultivated potato, Solanum tuberosum L. Potato Research, v.36, p.107-117. 1993.

DAVIES, H.V.; VIOLA, R. Regulation of sugar accumulation in stored potato tubers. Postharvest News and Information, v.3, p.97-100. 1992.

DEITING, U.; ZRENNER, R.; STITT, M. Similar temperature requirement for sugar accumulation and for the induction of new forms of sucrose phosphate synthase and amylase in cold-stored potato tubers. Plant, Cell and Environment, v.21, p.127-138. 1998.

DIXON, W.L.; REES, T. Carbohydrate metabolism during cold-induced sweetening of potato tubers. Phytochemistry, v.19, p.1653-1656. 1980.

EHNESS, R.; ROITSCH, T. Co-ordinated induction of mRNAs for extracellular invertase and a glucose transporter in Chenopodium rubrum by cytokinins. Planta, v.11, p.539-548. 1997.

GORNALL, A.G.; BARDAWILL, C.J. ; MAXIMA, D. Determination of serum proteins by means of the biuret reaction. Journal of Biology Chemistry, v.177, p.751-766. 1949.

HOFF, J.E.; LAM, S.L. ; ERICKSON, H.T Breeding for high protein and dry matter in the potato. West Lafayette: Purdue University. 23 p. Research Bulletin, 953. 1978.
Isherwood, F.A. Mechanism of starch-sugar interconversion in Solanum tuberosum. Phytochemistry, v.15, p.33-41, 1976.

ISLA, M.A.; LEAL, D.P.; VATTUONE, M.A. ; SAMPIETRO, A.R. Proteinaceous inhibitor from Solanum tuberosum invertase. Phytochemistry, v.30, p.739-743. 1991.

MELO, P.E. Cultivares de batata potencialmente úteis para o processamento na forma de fritura no Brasil e manejo para obtenção de tubérculos adequados. Informe Agropecuário, Belo Horizonte, v.20, p.112-119. 1999.

MORRIS, D.A.; ARTHUR, E.D. Invertase and auxin-indeced elongatiion in internodal segments of Phaseolus vulgaris. Phytochemistry, v.23, p.2163-2167. 1984.

NELSON, N.A A photometric adaptation of the Somogyi method for the determination of glucose. Journal of Biology Chemistry, v.153, p.375-380. 1944

O'DONOGHUE, E.P.; YADA, R.Y.; MARANGONI, A.G. Low temperature sweetening in potato tubers: the role of the amyloplast membrane. Journal of Plant Physiology, v.145, p.335-341. 1995.

PEREIRA, A. DA S.; COSTA, D.M.; VENDRUSCOLO, J.L.; DANIELS, F.J.; FORTES, G.R.; BERTOCINI, O.; HIRANO, E.; CHOER, E. ; AUGUSTIN, E. BRS Pérola: cultivar de batata adaptada a sistema de produção de pequenos produtores, para processamento de "batata palha”. Agropecuária Clima Temperado, Pelotas, v.3, p.287-290. 2000.

PINTO, J.E.B.; PINTO, C.A.B.; BARBOSA, M.H.P. Effects of different storage temperatures on protein quantities of potato tubers. Revista Brasileira de Fisiologia Vegetal, v.5,p.167-170. 1993.

POLLOCK, C.J.; REES, T. Activities of enzymes of sugar metabolism in cold-stored tubers of Solanum tuberosum. Phytochemistry, v.14, p.613617.1975.

PRESSEY, R. Invertase inhibitor from potatoes: Purification, characterization and reactivity with plant invertases. Plant Physiology, v.42, p.17801786. 1967.

PRESSEY, R.; SHAW, R. Effect of temperature on invertase, invertase inhibitor, and sugars in potato tubers. Plant Physiology, v.41, p.16571661. 1966
REES, T.; DIXON, W.L.; POLLOCK, C.J.; FRANKS, F. Low temperature sweetening of higher plants. In: Friend, J. ; Rhodes, M.J.C. (Ed.) Recent advances in the biochemistry of fruits and vegetables. New York: Academic Press. p.41-61. 1981.

RICHARDSON, D.L.; DAVIES, H.V.; ROSS, H.A.; MACKAY, G.R. Invertase activity and its relations to hexose accumulation in potato tubers. Journal of Experimental Botany, v.41, p.95-99. 1990.

ROBINSON, N.L.; HEWITT, J.D. ; BENNETT, A.B. Sink metabolism in tomato fruit. I. Development changes in carbohydrates metabolism enzymes. Plant Physiology, v.87, p.727-730. 1988.

SANDER, A., KRAUSGRILL, S.; GREINER, S.; WEIL, M.; RAUSCH, T. Sucrose protects cell wall invertase but not vacuolar invertase against proteinaceous inhibitor. FEBS Letters, v.385, p.171-175. 1996.

SONNEWALD, U.; HAJIREEEZAEI, M.R.; KOSSMANN, J.; HEYER, A; TRETHEWEY, R.N.; WILLMITZER, L. Increased potato tuber size resulting from apoplastic expression of a yeast invertase. Nature Biotechnology, v.15, p.794-797. 1997.

SOWOKINOS, J.R. Stress induced alterations in carbohydrate metabolism. In: Vayda, M.E. ; Park, W.D. (Eds.) The molecular and cellular biology of the potato. Wallingford: C.A.B. International. 137p. 1990.

STURM, A. Invertases. Primary structures, functions, and roles in plant development and sucrose partitioning. Plant Physiology, v.121, p.17. 1999.

TREVANION, S.J.; KRUGER, N.J. Effect of temperature on the kinetic properties of pyrophosphate: fructose 6-phosphate phosphotransferase from potato tuber. Journal of Plant Physiology, v.137, p.753-759. 1991.

ZRENNER, R.; SCHÜLER, K.; SONNEWALD, $\mathrm{U}$. Soluble acid invertase determines the hexoseto-sucrose ratio in cold-stored potato tubers. Planta, v.198, p.246-252. 1996. 